\title{
Joana Lopes e a Coreodramaturgia: Diálogos entre o jogo dramático e a arte do movimento de Rudolf Laban
}

\author{
José Rafael Madureira \\ Universidade Federal dos Vales do Jequitinhonha e Mucuri - UFVJM, Diamantina/MG, Brasil \\ E-mail: joserafaelmadureira@gmail.com \\ Andreia Ferreira Yonashiro \\ Universidade Federal do Rio de Janeiro - UFRJ, Rio de Janeiro/RJ, Brasil \\ E-mail: andreia_yonashiro@hotmail.com
}

\section{Resumo}

Artigo biográfico introdutório sobre a artista e pesquisadora Joana Lopes e seu procedimento investigativo denominado Coreodramaturgia. Joana Lopes desenhou uma longa trajetória como arte-educadora, jornalista, diretora teatral e dramaturga, tendo produzido obras monumentais que marcaram a cena paulista nos anos de 1980. Durante os mais de 20 anos em que atuou junto ao curso de graduação em Dança da Unicamp, Joana Lopes desenvolveu a Coreodramaturgia, uma escrita dramatúrgica para a dança. A Coreodramaturgia nasce do frutífero diálogo entre a Arte do Movimento de Rudolf Laban e o jogo dramático. Não por acaso, a Coreodramaturgia se tornou verbete atualizador do Dicionário Laban idealizado por Lenira Rengel. A Coreodramaturgia, enquanto metodologia de processo, já estava em gestação no Pega Teatro (1981), um livro que marcou toda uma geração de arte-educadores no Brasil e América Latina. A Coreodramaturgia estabelece uma relação íntima com a reteatralização, conceito-chave das revoluções teatrais do século $X X$, em especial com o expressionismo alemão na dança (Ausdruckstanz) e o Teatro-Dança (Tanztheater).

\section{Abstract}

Introductory biographical article about the artist and researcher Joana Lopes and her investigative procedure called Choreodramaturgy. Joana Lopes drew a long trajectory as an art-educator, journalist, theater director and playwright, having produced monumental works that marked the São Paulo scene in the 1980s. During the more than 20 years she worked with the undergraduate course in Dance at University of Campinas, São Paulo, Joana Lopes developed the Choreodramaturgy, a dramaturgical writing for dance. Choreodramaturgy arises from the fruitful dialogue between Rudolf Laban's Art of Movement and the dramatic game. It is not by chance that Choreodramaturgy became an updating entry for the Laban Dictionary designed by Lenira Rengel. Choreodramaturgy, as a process methodology, was already in gestation at Pega Teatro (1981), a book that marked a whole generation of art educators in Brazil and Latin America. Choreodramaturgy establishes an intimate relationship with reteatralization, a key concept of theatrical revolutions of the 20th century, especially with German expressionism in dance (Ausdruckstanz) and Dance Theater (Tanztheater). 
Joana Lopes desenhou uma longa trajetória como dramaturga, pesquisadora e arte-educadora. A filiação de seu trabalho com a Coreologia de Rudolf Laban é muito evidente em suas aulas, textos e criações poéticas. Não por acaso, seu procedimento investigativo, intitulado Coreodramaturgia, se tornou verbete do Dicionário Laban compilado por Lenira Rengel.

Neste artigo-homenagem, nos propomos a apresentar um pouco das andanças de Joana Lopes, situadas entre o teatro e a dança, e das bases da Coreodramaturgia, uma pesquisa realizada com extremo rigor acadêmico sobre o jogo dramático e seus diálogos com a Arte do Movimento de Rudolf Laban.

Esta narrativa estrutura-se através de documentos produzidos por Joana Lopes (livros, artigos, depoimentos) e materiais compilados por outros pesquisadores sobre sua obra e os desdobramentos desta na política, na arte e na educação. Todos esses dados são ratificados pela experiência que tivemos ao lado de Joana Lopes na condição de alunos, intérpretes-pesquisadores e colaboradores durante muitos anos.

\section{Uma breve nota biográfica}

Organizar uma linha biográfica de Joana Lopes não é tarefa fácil. Foram muitos encontros, desencontros, viagens pelo Brasil e exterior, mudanças de endereço, campos diversos de atuação, em resumo, uma existência nada linear. Por isso, nos limitaremos a traçar uma breve nota biográfica, pontuando apenas alguns episódios gerais, para que o leitor possa se contextualizar no tempo histórico e compreender as diversas camadas de uma obra complexa que não pode ser desmembrada da vida pessoal de sua autora. Esclarecemos ainda que esta nota foi escrita a partir das breves biografias escritas por Debértolis (2002) e Scialom (2009), além dos depoimentos citados neste trabalho e de várias conversas que tivemos com Joana Lopes desde 1995 até às vésperas da finalização deste artigo.

Joana Lopes nasceu em Belo Horizonte no ano de 1938 sob a regência de Marte. Sua biografia, uma verdadeira epopeia, poderia ins- pirar o libreto de uma ópera de Verdi ou o roteiro de um filme de Godard ou Glauber Rocha.

Ao longo de sua jornada poética, atuou ao lado de figuras emblemáticas da política, da arte e da educação, tais como Fayga Ostrower, Paulo Freire, Herbert de Souza, Jorge Mautner, José Roberto Aguilar, Lygia Clark, Hélio Oiticica, Caetano Veloso, Luís Otávio Burnier, Katherine Dunham, Marilia de Andrade, Maria Clara Machado, Ana Mae Barbosa, Carlos Drummond de Andrade, Gerda Alexander, Eugenia Casini Ropa, Françoise e Dominique Dupuy, Maria Duschenes e, com especial afeição, Klauss Vianna, amigo do tempo das aulas de balé com Carlos Leite e que a convidou, muitos anos depois, para contribuir com a árdua tarefa de reestruturação da Escola Municipal de Bailado de São Paulo. Klauss Vianna registrou essa parceria em seu livro-memorial: "Pedi a Joana Lopes que desse aulas de teatro, de interpretação, e os bailarinos começaram a perceber que a dança não é só essa coisa artificial e impostada que foram ensinados a acreditar" (VIANNA,1990, p. 48).

Joana Lopes mudou-se para São Paulo aos 12 anos. Casou-se aos 18 anos e muito jovem foi mãe de um casal de filhos. Depois de enfrentar um complicado desquite, buscou a sobrevivência em várias cidades entre São Paulo e Rio de Janeiro, atuando principalmente como alfabetizadora, à luz da metodologia freiriana, e professora de balé clássico.

Do Rio de Janeiro, depois de uma rápida passagem pela Escola de Arte do Brasil e pela Escola Nacional de Teatro, Joana Lopes se dirige ao Paraná, onde inicia, em 1971, um projeto de oficinas de teatro na Faculdade de FiIosofia da Universidade Estadual de Londrina.

O projeto foi consolidado e ela fundou o Teatro Escola Pindorama, que atendia à população marginalizada de lavadeiras e boias frias das plantações de café aglutinada no Conjunto Habitacional Pindorama.

Ao lado do trabalho como arte-educadora e dramaturga, Joana Lopes atuou como jornalista e militante do movimento feminista, tendo fundado ao lado de Terezinha Zerbini o jornal Brasil Mulher, primeiro tabloide feminista do Brasil, lançado em 1975, 
primeiro ano a instituir o dia internacional da mulher.

Esse engajamento em prol da defesa e emancipação feminina, somado às suas intervenções cênicas que colocavam em xeque a ordem estabelecida, Ihe rendeu muita perseguição política e o protagonismo da dissertação de mestrado intitulada Brasil MuIher: Joana Lopes e a imprensa alternativa feminista, defendida em 2002 por Karen Silvia Debértolis no Programa de Pós-Graduação em Comunicação e Informação da Universidade Federal do Rio Grande do Sul.

As tensões políticas agravaram-se seriamente. Em 1979, ela foi obrigada a deixar o jornal, a universidade e os projetos de teatro-educação para recomeçar a vida mais uma vez na capital paulistana.

De volta a São Paulo, Joana Lopes conheceu Maria Duschenes, que the apresentou os fundamentos da Arte do Movimento de Rudolf Laban através de "uma abordagem surpreendente", como ela mesma declarou no depoimento concedido a Rafael Petri em 2016 para o projeto Maria Duschenes: expressão de liberdade, idealizado pelo Museu da Dança e Maria Mommensohn. No mesmo depoimento, Joana Lopes fala das motivações que a levaram à Maria Duschenes:

Eu cheguei até Maria Duschenes buscando uma alternativa para a dança clássica, para ver como eu iria desconstruir aquilo e para ver se existia alguma alternativa dentro daquilo que eu estava vislumbrando como uma área de curiosidade ainda para mim que era o jogo dramático, o teatro e a educação. ${ }^{1}$

O referencial labaniano, na perspectiva de Maria Duschenes, se revelou como a peça-chave que faltava para ampliar e potencializar a pesquisa que Joana Lopes estava realizando no campo do teatro-educação sobre jogo dramático e dramaturgia.

O retorno a São Paulo foi muito auspicioso para sua carreira como diretora teatral e dramaturga, período no qual ela criou duas obras monumentais: Vespe-

1 Esse depoimento, entre vários outros, pode ser apreciado no site do Museu da Dança. Disponível em: http://www. museudadanca.com.br/maria-duschenes/\#depoimentos. Acesso em: 24 mai. 2020. ral Paulistânia e Tribunal Tiradentes², ambas de 1983.

Toda essa visibilidade como artista, somada ao trabalho pedagógico realizado ao lado de Klauss Vianna no Teatro Municipal e, algum tempo antes, na escola de arte dirigida por Ana Mae Barbosa, despertou a atenção de Marília de Andrade, que a convidou para participar da fundação do Departamento de Artes Corporais da Universidade Estadual de Campinas em 1985. Joana Lopes também contribuiu por algum tempo com o trabalho dos atores do Núcleo Interdisciplinar de Pesquisas Teatrais da Unicamp - LUME, fundado nesse mesmo ano por Luís Otávio Burnier.

Joana Lopes atuou por mais de 20 anos como docente do curso de graduação em Dança da Unicamp, responsável pelas unidades curriculares Arte-Educação, Expressão Dramática na Dança e Expressão e Movimento I e II que, a propósito, sempre se articularam ao pensamento labaniano. Ainda na Unicamp, atuou como pesquisadora-líder do Grupo Interdisciplinar em Teatro e Dança (GITD), criado por ela em 1993 e integrado ao Núcleo Interdisciplinar de Comunicação Sonora (NICS/Unicamp), coordenado por vários pesquisadores, destacando-se os parceiros de trabalho Raul do Valle, Jônatas Manzolli e Adolfo Maia Júnior.

O ingresso na Unicamp foi uma grande oportunidade de aglutinação de seus esforços como artista e pesquisadora: "Aliei o ensino na universidade a minha obra como diretora e coreodramaturga [...] Enfim, o teatro coreográfico na vertente labaniana" (LOPES, 2017, p. 253).

Joana Lopes também esteve bastante presente nos debates internacionais promovidos pelo Institut de Pédagogie Musicale et Chorégraphique de Paris (IPMC) assim como contribuiu com a revista Marsyas, editada por Dominique Dupuy, através do artigo La tradition ou la maîtresse invisible (LOPES, 1994), posteriormente traduzido para o português e publicado na revista Repertório (LOPES, 2016).

2 Mais informações sobre essas obras podem ser consultadas no site pessoal de Joana Lopes. Disponível em: https:// www.joanabizzottolopes.com/. Acesso em 24 mai. 2020. 
Através de seus esforços pessoais, diversos estudantes brasileiros puderam participar desses colóquios, especialmente aqueles organizados por Françoise e Dominique Dupuy no Centre d'Études et Recherches en Danse Contemporaine - Mas de la Danse, situado em Fontvieille, que reuniram grandes nomes da intelectualidade francesa como Laurence Louppe, Hubert Godard e Michel Bernard.

$\mathrm{Na}$ Itália, mais especificamente no Departamento de Música e Espetáculo da Universidade de Bolonha - Alma Mater Studiorum, Joana Lopes atuou como professora visitante por 10 anos a convite de Eugenia Casini Ropa, sua grande amiga e interlocutora que esteve no Brasil em diversas ocasiões para ministar seminários sobre Laban e a historiografia da dança moderna. Importante destacar que Eugenia Casini Ropa organizou, ao lado de Silvia Salvagno e com a colaboração de Joana Lopes, a versão italiana da obra Domínio do Movimento (LABAN, 1978), publicada sob o título de L'Arte del Movimento (LABAN, 1999).

Entre todos esses eventos protagonizados por Eugenia Casini Ropa no Brasil, quase sempre traduzidos e mediados por Joana Lopes, destacamos a conferência O Corpo Cênico: Laban e a Dança do século XX, proferida em 1996 durante a programação do $4^{\circ}$ Encontro Laban, que incluiu palestras, cursos, oficinas, mesas, sessões de vídeos e espetáculos coreográficos $^{3}$. Paulo Petrella (2006, p. 12) destacou que essa edição do Encontro Laban foi vivida com grande entusiasmo pelos participantes, o que mobilizou a escrita de alguns dos textos apresentados na coletânea sobre Laban organizada por ele e Maria Mommensohn (MOMMENSOHN; PETRELLA, 2006).

Joana Lopes também esteve presente nessa memorável edição do Encontro Laban e ministrou o curso prático-teórico Coreodramaturgia: Método Psicolinguístico de Treinamento do Ator, com duração de 18 horas (20 vagas), uma experiência importante para

30 programa completo do $4^{\circ}$ Encontro Laban pode ser consultado no acervo do Museu da Dança. Disponível em: http://acervomuseudadanca.com.br/wp-content/uploads/2016/10/l-6.pdf. Acesso em: 24 mai. 2020. o amadurecimento de suas proposições que seriam divulgadas em um caderno didático pouco tempo depois.

Além das produções como jornalista, acadêmica e dramaturga, Joana Lopes também escreveu: Pega Teatro (LOPES, 1981), um clássico sobre as origens do teatro-educação no Brasil, A Encenação do Didático (LOPES, 1987), um ensaio publicado na coletânea Brecht no Brasil, organizada por Wolfgang Bader (1987), e o livro infanto-juvenil Pedrina e o Mar (LOPES, 1988), baseado em suas memórias de infância.

\section{Fundamentação da pesquisa sobre o teatro-educação}

Joana Lopes pertence à geração de artistas e intelectuais da década de 1960 que atuou sob um ideal libertário. Na perspectiva da educação, seu posicionamento era radicalmente contrário a imposição de modelos, valores ou orientações estéticas que impediriam a descoberta e auto-organização expressiva. Na perspectiva do teatro, foi lançado o desafio de criar processos compositivos que não obedecessem à tradição histórica que submete a atuação do ator à autoria de um dramaturgo ou à encenação de um diretor.

Joana Lopes encontrou no jogo o seu campo de pesquisa, atuação e criação. Conforme suas observações: "Desde que nascemos, jogamos de modo intuitivo e, pouco a pouco, percebemos que é possível ser o outro, fingir o outro, representar o outro". (LOPES, 2009, p. 25). É esse "pouco a pouco" que Joana Lopes, de maneira participativa e perspicaz, observa nas brincadeiras das crianças, nos brincantes do teatro popular e nos atores amadores ou profissionais. Assim, sua obra dá visibilidade às nuances e características que marcam essa transição entre ludicidade (paidia) e o jogo dramático.

Esse é o assunto principal do seu ensaio seminal Evolução do Jogo Dramático, escrito em 1976 e mimeografado centenas de vezes para ser difundido de mãos em mãos pelo Brasil e América Latina. Nesse texto, Joana Lopes reconhece a dramatização como vetor que ao mesmo tempo traduz e organiza a expressão corporal do jogo. Esse tipo de 
acontecimento é o centro de sua atenção, que dá passagem às suas considerações sobre a importância da metamorfose no jogo dramático, uma tese desenvolvida no Pega Teatro. Para Joana Lopes:

Na dramatização espontânea, o atuante não é um mediador da expressão criada por um dramaturgo, interpretada por um diretor de cena, juntamente com seu grupo de atores. No jogo dramático espontâneo, o atuante é fonte de expressão, fazendo o jogo do autor-ator, portanto a metamorfose, fenômeno básico desse jogo, aparecerá como resposta genuína do atuante interessado em transformar-se num outro, o que significa ampliar seu universo de comunicação, sua capacidade de expressão e sua criatividade. (LOPES, 2017, p. 96).

O atuante é aquele que mergulha no jogo e sai moIhado, apesar de suas roupas continuarem secas. Simultaneamente, ele é fonte de expressão e dramatização.

Joana Lopes (1989, p. 9) define o jogo dramático como "exercício poético de e para a liberdade", evidenciando um engajamento na vertente do teatro-educação na América Latina e uma espécie de militância por um imaginário não europeu, repetindo a máxima "toda imaginação ao poder" (LOPES, 2017, p. 33).

No prefácio da terceira edição de Pega Teatro, Leila Jeolás situa com precisão a atuação de Joana Lopes no campo do teatro-educação:

Por estar situado na interação da arte e da educação, o trabalho sensível e comprometido de Joana Lopes ultrapassa limites deste desafio, escuta o Outro e se engaja nele - grupos populares, operários/ as, lavadeiras e crianças de bairros periféricos, estudantes - na construção de uma ação-expressão, através de seus próprios jogos de comunicação, que transforma todos e cada um em direção à emancipação, criando a possibilidade de metamorfose através da ampliação da capacidade da expressão dramática. (JOELÁS, 2017, p. 19).

Quando Joana Lopes cruza o oceano, literalmente, se depara com o termo reteatralização (riteatralizzazione), que é fundamental para localizarmos o momento em que a Coreologia de Ru- dolf Laban passa a integrar seu campo de pesquisa com mais intensidade, confirmando suas primeiras impressões e estudos com Maria Duschenes.

A reteatralização como conceito histórico-social foi apresentado à Joana Lopes por Eugenia Casini Ropa, autora de uma obra de referência sobre o teatro do século XX (ROPA, 1988) que foi traduzida para o português em 2014 e da qual extraímos a seguinte sentença:

Uma das palavras de ordem mais eficazes e persistentes do teatro do século $X X$ foi certamente reteatralização. $E$ à luz desse termo nasceram - e foram sobretudo explicadas e teorizadas em seguida - as reflexões e as experimentações que caracterizaram e traçaram os rumos do teatro do início do século XX. (ROPA, 2014, p. ix).

Esse conceito dialoga com as premissas fundamentais do teatro-educação de Joana Lopes. Nessa abertura, o teatro-educação revolucionário de Asja Lacis, bem como as ideias sobre a reteatralização do movimento gestadas por Rudolf Laban, Bertolt Brecht e Jean Weidt, o dançarino vermelho, são incorporadas ao seu trabalho.

Nesse sentido, Joana Lopes percebe na Coreologia de Laban uma forte ressonância com a sua proposição de que o atuante é a fonte de expressão. Desse modo, ela passa a reconhecer, na dança, uma expressão dramática fundamentada na íntima e mútua relação entre a metamorfose do jogo e a Arte do Movimento, o que irá consolidar uma nova escrita dramatúrgica, a Coreodramaturgia.

\section{Coreodramaturgia:} uma dramaturgia para a dança

Em 1998, depois de quase 20 anos de pesquisa com base no diálogo entre o jogo dramático e o corpus teórico labaniano, Joana Lopes publicou o caderno didático Coreodramaturgia: a Dramaturgia do Movimento (LOPES, 1998). A tiragem, feita na gráfica da Unicamp, foi pequena (70 cópias), o que a motivou a publicar, uma nova versão, cujo subtítulo sofreu uma 
alteração bastante significativa: Coreodramaturgia: uma Dramaturgia para a Dança (LOPES, 2007). A substituição do artigo definido "a" pelo artigo indefinido "uma" já indica um recuo, uma ponderação, pois a Coreodramaturgia deveria ser pensada como apenas uma possibilidade de escrita dramatúrgica do movimento entre tantas outras. A redefinição de um campo, no caso, a dança, também é muito reveladora, o que não havia sido anteriormente explicitado.

Joana Lopes reconheceu as limitações do caderno e prometeu publicar um segundo volume para tratar especificamente dos procedimentos coreodramatúrgicos, o que até o presente momento não aconteceu. Conforme Joana Lopes, o caderno foi criado para "responder às necessidades da disciplina Expressão Dramática na Dança" (2007, p. 13), da qual ela foi docente responsável desde sua primeira oferta no curso de Graduação em Dança da Unicamp.

A ementa da unidade curricular AD713 - Expressão Dramática na Dança permaneceu inalterada desde a fundação do curso de Graduação em Dança até 2018, tendo sido excluída da matriz curricular em $2019^{4}$. Nessa ementa, observamos os conceitos-chave da Coreodramaturgia: "O curso se destina a desenvolver o jogo dramático dos alunos de dança, considerando-o a gênese do fenômeno teatral" (UNICAMP, 1995, p. 222, grifo nosso).

Joana Lopes realmente considera que a essência do fenômeno teatral se localiza no jogo, no jogo dramático, o que também pode ser aplicado à dança ou, mais propriamente, à tradição do teatro-dança, o Tanztheater, nascido do expressionismo alemão na dança (o Ausdruckstanz de Laban, Wigman e Jooss) ao qual ela afirma ter uma "filiação estética" (LOPES, 2017).

A Coreodramaturgia como procedimento investigativo conquistou maior alcance no Brasil ao

4 Conforme consulta feita com o suporte da gestora Kelly Cristina Silva (DAC/UNICAMP), a quem agradecemos imensamente pela generosidade e disposição em nos ajudar. Os demais Catálogos de Graduação, de 1998 a 2020, podem ser consultados no site da DAC/UNICAMP. Disponível em: https://www.dac.unicamp.br/portal/graduacao/catalogos-de-cursos. Acesso em: 24 mai. 2020. ser apresentada no Dicionário Laban idealizado por Lenira Rengel. Nesse precioso material, a Coreogramaturgia aparece como "verbete atualizador", categoria de termos e conceitos criada para abarcar pensadores, professores, coreógrafos ou estudiosos que, conforme Rengel (2001, p. 11), "se utilizam da Teoria de Movimento de Laban e a desenvolveram, criando ou não novos movimentos-palavras" A Coreodramaturgia compreende o verbete $n^{\circ} 31$ desse Dicionário, definido como:

\begin{abstract}
Sistema de escritura cênica para atores, atores-bailarinos, performers, arte-educadores. Conceito que nasceu da pesquisa denominada Do Movimento a Palavra, da Palavra ao Movimento. Aplicado na criação dramatúrgica do Teatro-Dança e nos eventos da Arte do Movimento. Define-se como contribuição à Coreologia de Rudolf Laban e é fundado nos princípios elementares desta teoria. Estilisticamente configura-se como neoexpressionismo e designa uma obra de perfil interdisciplinar. (RENGEL, 2014, p. 40).
\end{abstract}

De acordo com Lenira Rengel (2001), essa definição foi apresentada pela própria Joana Lopes em uma entrevista concedida especialmente para a elaboração do Dicionário. Devido às limitações de um dicionário, o verbete não é discutido, o que torna a compreensão sobre a Coreodramaturgia pouco inteligível.

Joana Lopes sempre definiu campos experimentais para realizar suas intervenções artísticas e pedagógicas. Em seu depoimento concedido à Coleção Percursos da Arte na Educação ${ }^{5}$, ela insiste no conceito de "metodologia de processo", uma orientação metodológica a ser estabelecida durante o processo de investigação criativa e que se contrapõe a qualquer tendência tradicional-tecnicista. No mesmo depoimento, confirmado por outros documentos (LOPES, 2009) ela afirma ter aprendido com Fayga Ostrower, sua mestra, o ver-

5 Este depoimento, produzido pela ONG Ação Educativa
e pelo Instituto C\&A (2013, 25 min.), compõe a coleção
Percursos da Arte na Educação, um projeto que escolheu
e reuniu 20 arte-educadores reconhecidos pela sua con-
tribuição ao desenvolvimento do ensino de arte no Brasil. 
dadeiro sentido da materialidade na arte, argumentando que caberia ao artista-educador desvendá-la de acordo com a sua própria linguagem artística. A Coreodramaturgia é justamente essa "metodologia de processo" que impulsiona o desvelar da materialidade do corpo, no teatro como na dança.

O processo coreodramatúrgico origina-se do jogo, mais especificamente do jogo dramático. Este, por sua vez, nasce dos "jogos arcaicos", conceito amplamente utilizado por Joana Lopes (2007, 2009, 2017) e que circunscreve as brincadeiras da infância ou paidia, termo grego designado por Huizinga (2010, p. 35) como "aquilo que é próprio da criança". Em Caillois (2017, p. 69), autor de referência para Joana Lopes ao lado de Huizinga, a paidia compreende "as manifestações espontâneas do instinto do jogo".

Joana Lopes esclarece que essa íntima relação entre a Coreodramaturgia e os jogos arcaicos se dá porque eles "atravessam o tempo pelo tempo social contemporâneo para se embrenhar na trama da existência humana" (2017, p. 36).

Não podemos confundir jogos arcaicos (paidia) com comportamentos infantilizados. Para Huizinga "a criança joga e brinca dentro da mais perfeita seriedade, que a justo título podemos considerar sagrada. Mas sabe perfeitamente que o que está fazendo é um jogo" (2010, p. 21). Em Caillois (2017), observamos que o jogo evolui de um estado mais pueril, instintivo, espontâneo e despreocupado (paidia) para um fazer extremamente sofisticado (ludus), com altíssimos níveis de destreza técnica, no sentido da techné apresentado por Heidegger (2007).

Esses pensamentos de Huizinga e Caillois fundamentam a discussão sobre "as fases evolutivas do jogo dramático" apresentada por Joana Lopes no Pega Teatro (1981, 1989 e 2017), e também orientam a "metodologia de processo" coreodramatúrgica. Joana Lopes observa ainda que:

Em termos da transformação de um jogo simples, como é caça e caçador, passamos dos valores arcaicos do protagonista e do antagonista do jogo dramático para um jogo especial alcançando os sentidos da linguagem ou o jogo dramático, que evolui na medida de sua prática lúdica para lúdica artística que identificamos como arte. (LOPES, 2017, p. 36).

Joana Lopes também se vale da organização dos jogos proposta por Caillois (2017), na qual todos os jogos poderiam ser organizados em quatro categorias: Agôn (jogos de destreza física), Alea (jogos de sorte), Ilinx (jogos de vertigem) e Mimicry (jogos de imitação).

A escolha dos jogos arcaicos não é aleatória, ela acontece com base em algum material estético (um texto dramático ou literário, um filme, uma ópera, um espetáculo coreográfico), que oferece um universo dramático a ser explorado, personagens e, sobretudo, ações dramáticas.

Assim, brincar de pega-pega ou qualquer outro jogo arcaico, por exemplo, é o ponto de partida para a construção rítmica e corporal da Coreodramaturgia. Depois de rememorar os jogos da infância e localizar cada jogo arcaico em uma ou mais categorias de jogo, cabe aos intérpretes-jogadores fazer a análise das ações corporais experimentadas com base no referencial labaniano, da harmonia espacial, considerada por Joana Lopes (2007, p. 3) como "passagem obrigatória para a Coreodramaturgia”, à análise eucinética dos esforços.

O trabalho de Sotratto et al. (2007), baseado em Alice no País das Maravilhas, de Lewis Carroll, traz um esquema (quadro 1) dessa articulação entre os jogos arcaicos, as categorias de Caillois e o material dramatúrgico gerador. 
Quadro 1 - Esquema do Jogo x Categoria x Metáforas

\begin{tabular}{|c|c|l|}
\hline Jogo & Categoria & $\begin{array}{c}\text { Metáfora em } \\
\text { "Alice" }\end{array}$ \\
\hline $\begin{array}{c}\text { CORRIDA DA } \\
\text { COLHER }\end{array}$ & Agôn & $\begin{array}{l}\text { Alice está } \\
\text { entendiada } \\
\text { quando Acontece } \\
\text { algo } \\
\text { Extraordinário. }\end{array}$ \\
\hline $\begin{array}{c}\text { DANÇA DA } \\
\text { LARANJA }\end{array}$ & Alea e Inlix & $\begin{array}{l}\text { Alice corre de } \\
\text { mãos dadas } \\
\text { com a Rainha } \\
\text { Vermelha, mas as } \\
\text { árvores e tudo em } \\
\text { volta não saem } \\
\text { do lugar. }\end{array}$ \\
\hline JOGO DOS PÉS & Agôn & $\begin{array}{l}\text { Alice participa de } \\
\text { um Chá Maluco. }\end{array}$ \\
\hline PALITO CHINÊS & Agôn e Alea & $\begin{array}{l}\text { Todas as } \\
\text { mudanças que } \\
\text { acontecem em } \\
\text { volta de Alice } \\
\text { enquanto ela está } \\
\text { do outro lado do } \\
\text { Espelho. }\end{array}$ \\
\hline CABRA CEGA & Agôn e llinx & $\begin{array}{l}\text { Alice está na loja } \\
\text { com a Ovelha } \\
\text { e tenta olhar as } \\
\text { coisas que estão } \\
\text { nas prateleiras, } \\
\text { mas as coisas } \\
\text { são fugidias. }\end{array}$ \\
\hline
\end{tabular}

Fonte: Sotratto et al., 2007, p. 57.

A escrita coreodramatúrgica passa pela associação de uma escrita espacial através da espacialidade dos jogos arcaicos e combinada a uma leitura que articula os verbos de ação (do texto dramático) à ação básica ou conteúdo dinâmico e à dinâmica expressiva (ações corporais básicas). No próximo esquema (quadro 2), temos um exemplo dessa construção, realizada para a peça Círculo de Fogo, criada por Joana Lopes em 1996.
Quadro 2 - Jogo arcaico "lenço atrás"

\begin{tabular}{|l|l|l|}
\hline \multicolumn{3}{|c|}{ MOVIMENTO DO SOLDADO } \\
\hline Verbos & Ação básica & $\begin{array}{l}\text { Dinâmica } \\
\text { expressiva }\end{array}$ \\
\hline Cumprimentar & Rodar & Deslizar \\
\hline Feder & Balançar & Pressionar \\
\hline Lamber & Arquear & Pressionar \\
\hline Morder & Fechar & Bater \\
\hline Ir & Precipitar-se & Pontuar \\
\hline
\end{tabular}

Fonte: Baseado no esquema de Lopes, 1997, p. 216.

A fonte principal utilizada por Joana Lopes para fundamentar a relação do jogo dramático com as teorias de Laban é Domínio do Movimento, publicada no Brasil em 1978. Joana Lopes, todavia, nunca gostou muito dessa versão, que ocultava do título o termo "palco" (stage) que, para ela, era essencial. De fato, a obra original organizada por Lisa Ullmman em 1950 intitula-se The Mastery of Movement on the Stage (grifo nosso).

Scialom (2009) também descreve esse questionamento sobre a tradução, acrescentando que, para Joana Lopes, a compreensão sobre a Arte do Movimento de Laban, por muito tempo, foi bastante limitada e equivocada. Para Joana Lopes (apud SCIALOM, 2009 , p. 164), "Laban, no Brasil, é aceito enquanto o teórico da dança educativa. A livre expressão se associa a Laban de uma forma quase absoluta".

Devido à sua proximidade com Eugenia Casini Ropa, Joana Lopes se apegou à tradução italiana de The Mastery of Movement on the Stage, embora essa versão, como foi anteriormente explicitado, também tenha modificado o título original por L'Arte del Movimento (LABAN, 1999), seguindo a escolha não arbitrária da versão alemã Die Kunst der Bewegung (A Arte do Movimento), realizada por Karin Vial e Claude Perrottet (LABAN, 1988).

A versão italiana, realizada com base nas primeiras edições da obra original, complementa a edição com o apêndice Alcuni aspet- 
ti fondamentali della struttura dello sforzo (Alguns aspectos fundamentais da estrutura do esforço), que não consta na edição em português.

O instigante apêndice (LABAN, 1999, p. 168187) é subtividido em 14 partes: O esforço em geral, Mutações, Classificações, Combinações de fluxo, Graus de intensidade, Os quatro graus de intensidade, As três alterações de um esforço, Limitações no uso dos fatores de movimento, Aumento ou diminuição dos graus dos elementos de esforço, A construção de um esforço, Transições, Recuperação e elasticidade, Ritmo de uma sequência de esforço, Movimento sombra.

Através desse material, Joana Lopes encontra elementos para um aprofundamento dos estudos da Eucinética no campo do jogo dramático.

Durante os anos de pesquisa da Coreodramaturgia, Joana Lopes sentiu a necessidade de criar um protocolo de estudos do movimento (treinamento) denominado Gesto Relacional Ampliado ou GERA, que deveria ser praticado com muita consciência e presença, de modo a impulsionar a passagem de um contexto pré-dramatúrgico ao dramatúrgico. O GERA revisita a noção brechtiana do gestus, sendo que o "relacional" se concretiza quando o atuante redescobre o seu corpo como um sistema de alavancas.

Para Theda Cabrera (2004), o protocolo GERA delimita um conjunto de exercícios físico-linguísticos de treinamento do dançarino-ator dirigidos à percepção da origem corporal do gesto dramático. Ainda em Cabrera (2004, p. 30), trata-se do "como construir o corpo cênico partindo das sensações de movimentos pré-dramatúrgicos e transformando-os em dramatúrgicos".

Se a prática das escalas propostas no estudo da harmonia espacial privilegia um estudo autocentrado, estável e circunscrito nos sólidos de Platão, no GERA a desestabilização trazida pela relação com o outro é muito desejável, pois ela se aproxima das metamorfoses essencialmente instáveis trazidas pelo jogo.

Do ponto de vista da corporeidade, a liberação do corpo de uma restrição determinada pela geometria clássica pode ser conquistada na articulação entre o GERA e o estudo das qualidades dos esforços presentes no jogo. Esse protocolo é especialmente importante quando Joana Lopes trabalha com bailarinos que, em geral, trazem no corpo as marcas de uma especialização técnica condicionante.

\section{Algumas produções coreodramatúrgicas}

A visão panorâmica que temos do processo investigativo em Coreodramaturgia contempla a criação e escrita coreodramatúrgica de algumas obras, que descreveremos em seguida. Em cada uma delas, Joana Lopes privilegia elementos específicos, testando e ampliando os limites do seu trabalho ${ }^{6}$. Scialom (2015, p. 117) observou ainda que, ao propor uma forma original de explorar os princípios do movimento de Laban, Joana Lopes acabou engendrando um repertório.

\section{- A travessia do Atlântico de Ginga}

Band (1993), uma obra didática, um Samba com enredo coreodramatúrgico. Nessa obra, Joana Lopes sintetiza o estudo das danças populares no Brasil e do fenômeno da Escola de Samba, uma paixão que ela registrou no artigo Tradição ou a Mestra Invisível, publicado inicialmente em francês na revista Marsyas (LOPES, 1994) e traduzido e publicado, 20 anos depois, na revista Repertório (LOPES, 2016). A riqueza rítmico-espacial das dramatizações populares ofereceu à Joana Lopes mais uma porta de entrada na espacialidade do jogo e que ela aplica em cursos e seminários com alunos do mundo inteiro, realizando um estudo comparado dos jogos tradicionais.

6 Outros detalhamentos técnicos, fotos e vídeos sobre essas montagens podem ser consultados no site pessoal de Joana Lopes (vide nota $n^{\circ} 2$ ). 


\section{- O Círculo de Fogo ou a Traição de} um Juiz (1996), criada a partir da obra O Círculo de Giz Caucasiano de Brecht (1948). Trata-se de uma coreodramaturgia escrita na forma dialógica, com indicações de canções, falas e ações, indicadas em um roteiro paralelo que indica as associações entre verbos, ações corporais básicas e dinâmicas expressivas.

- Jogos de D. e O. (1999), baseada no Otelo de Shakespeare (1604). Nessa obra, os jogos arcaicos são vividos com muita precisão rítmica, o que conduz a construção dramática através de um desenho compositivo, uma transição dos esforços que animam a dança dos atores em cena.

\section{- Para que servem as Estrelas?} (2004), trabalho acadêmico de conclusão do curso de Graduação em Dança da Unicamp orientado por Joana Lopes ${ }^{7}$ e baseado no romeance A hora da Estrela, de Clarice Lispector (1977). Nessa obra, as combinações entre os esforços resultam em trechos coreográficos que são dinamizados por jogos arcaicos.

- InLudere (2007), outro trabalho acadêmico de conclusão do curso de Graduação em Dança da Unicamp orientado por Joana Lopes $^{8}$ e realizado através da leitura de Alice no país das Maravilhas de Lewis Carrol (1865). Nessa criação, a instabilidade do movimento presente nos jogos arcaicos é estudada através dos princípios de análise cinesiológica. Esse tipo de leitura cinesiológica do movimen-

7 Sobre este processo de criação, consultar: Coelho et al. (2004) e Scialom (2010).

8 Sobre este processo de criação, consultar: Sotratto et al. (2007). to é utilizada como recurso de escrita da dimensão organizacional do movimento no contexto do jogo, e em suas combinações entre as categorias de Caillois.

- Prá Weidt - o velho (2007), uma coreodramaturgia escrita com base na coreografia Vieilles Gens, Vieux Fers (1928) de Jean Weidt que foi remontada em 1948 com a interpretação de Françoise e Dominique Dupuy, entre outros bailarinos. A versão de Joana Lopes inspira-se na realidade brasileira e se realiza com 11 bailarinos jovens e 11 idosos em cena.

- A flor boiando além da escuridão (2008), coreodramaturgia criada a partir da leitura das Cores Proibidas de Yukio Mishima (1951) e da análise de trechos coreográficos de bailarinos expressionistas que influenciaram a dança de Kazuo Ohno, como Mary Wigman, além de citações da própria dança de Kazuo Ohno. Trabalho solo interpretado por Andreia Yonashiro.

\section{Considerações finais}

Joana Lopes já está aposentada há mais de 10 anos, o que, para ela, não significou a conclusão de uma brilhante carreira, muito pelo contrário. Durante esse período, ela deu continuidade às pesquisas sobre dança e jogo dramático e delimitou um novo campo de pesquisa: a Coreotopologia.

Não nos cabe, neste momento, fazer descrever essa nova "metodologia de processo", mas é importante registrar que a Coreotopologia buscou um cruzamento entre alguns conceitos-chave da Física Relativística e da Topologia e o campo da composição em dança.

A Coreotopologia, assim como a Coreodramaturgia, também parte de uma revisão rigorosa da Coreologia de Laban, uma obra que, como sabemos, 
permanece atual e aberta a interpretações e desdobramentos. Joana Lopes apresenta um detalhamento completo da Coreotopologia no livro A dança elementar (2020), prefaciado por Eugenia Casini Ropa.

Finalizamos este artigo-homenagem ressaltando a gratidão que temos pela mestra que abriu os nossos olhos e corações para os férteis campos que hoje semeamos. Nós não somos os únicos a reconhecer o papel de Joana Lopes na formação de artistas e pesquisadores brasileiros de várias gerações: "Agradecimentos à Joana Lopes, pelo brilho dos seus olhos ao me ensinar" (RENGEL, 2001, p. 4); "Joana Lopes, minha madrinha do pensamento Labaniano" (LACAVA apud SCIALOM, 2009, p. 175); "O encontro com Joana Lopes foi marcante, pois despertou uma inquietação quanto à materialidade do fazer cênico" (CABRERA, 2004, p. 19); "Agradeço à Joana Lopes, pedagoga e artista que me introduziu ao universo labaniano" (SCIALOM, 2009, p. 6).

No campo do ativismo político, o reconhecimento foi declarado no dia quatro de abril de 2008, quando Joana Lopes, juntamente com Ziraldo e outros 18 jornalistas, foi anistiada pelo Ministério da Justiça.

\section{Referências}

BADER, W. (Org.). Brecht no Brasil: experiências e influências. Rio de Janeiro: Editora Paz e Terra, 1987.

CABRERA, T. Uma aprendizagem de sabores: a palavra construída a partir da conexão entre movimento, emoção e voz. 2004. 158 f. Dissertação (Mestrado em Artes da Cena). Instituto de Artes, Universidade Estadual de Campinas. Campinas, São Paulo. 2004.

CAILLOIS, R. Os jogos e os homens: a máscara e a vertigem. Tradução de Maria Ferreira. Petrópolis: Vozes, 2017.
COELHO, M.; FERNANDES, R.; LAETANO, D.; SCIALOM, M.; SIQUEIRA, C.; YONASHIRO, A. F. Expressão Brasileira - um estudo sobre as interfaces do Teatro-Dança. Campinas. 2004. Trabalho de Conclusão do Curso (Graduação em Dança). Departamento de Artes Corporais, Instituto de Artes, Universidade Estadual de Campinas. Campinas, São Paulo.

DEBÉRTOLIS, Karen Silvia. Brasil mulher: Joana Lopes e a imprensa alternativa feminista. 2002. Dissertação (Mestrado em Comunicação e Informação). Universidade Federal do Rio Grande do Sul. Porto Alegre, 2002.

HEIDEGGER, M. A questão da técnica. Tradução de Marco Aurélio Werle. Scientiæ Studia, São Paulo, v. 5, n. 3, 2007, p. 375-398.

HUIZINGA, J. Homo Ludens: o jogo como elemento da cultura. Tradução de João Paulo Monteiro. 6. Ed. São Paulo: Perspectiva, 2010.

LABAN, R. Domínio do Movimento. Tradução de Anna Maria Barros De Vecchi e Maria Sílvia Mourão Netto. São Paulo: Summus, 1978.

Die Kunst der Bewegung. Tradução de Karin Vial e Claude Perrottet. Wilhelmshaven: Florian Noetzel Verlag, 1988.

. L'Arte del Movimento. Tradução de Silvia Salvagno e curadoria de Eugenia Casini Ropa. Macerata: Ephemeria Editrice, 1999.

LOPES, J. Pega Teatro. São Paulo: Centro de Teatro e Educação Popular, 1981.

Encenação do didático (ou uma maneira de ser estética numa perspectiva didática) In: BADER, W. (org.). Brecht no Brasil: experiências e influências. Rio de Janeiro: Editora Paz e Terra, 1987, p. 107-118. 
. Pedrina e o Mar. São Paulo: Companhia Editora Nacional, 1988.

Pega Teatro. 2. Ed. Campinas: Papirus, 1989.

. La tradition ou la maîtresse invisible, Marsyas

(IPMC), Paris, n. 31, set. 1994, p. 64-68.

O Teatro Antropomágico: dança - som - palavra. 1997. Tese. 308 f. (Concurso para Professor Artista Pleno). Departamento de Artes Corporais, Instituto de Artes, Universidade Estadual de Campinas, Campinas, São Paulo.

Coreodramaturgia: a dramaturgia do movimento. Campinas: Instituto de Artes da UNICAMP, 1998. (caderno pedagógico).

Coreodramaturgia: uma dramaturgia para a dança. Santos: Comunnicar Editora, 2007. (caderno pedagógico).

Da arte-educação à arte ampliada: o percurso da memória e da história. Seminário Ações Singulares II - História do Ensino da Arte: Experiências. Instituto Tomie Otake, São Paulo, 2009, p. 22-29.

. A tradição ou a mestra invisível. Tradução de José Rafael Madureira e Nirvana Marinho. Repertório (UFBA), Salvador, n. 26, 2016, p. 229-236. Disponível em: https://portalseer.ufba.br/index.php/revteatro/article/view/17473/11413. Acesso em 27/05/2020.

Pega Teatro. 3. Ed. Bragança Paulista: Urutaú, 2017.

. Dança Elementar. São Paulo: Stacchini Editorial, 2020.

MOMENSOHN, M.; PETRELLA, P. (Orgs.). Reflexões sobre Laban, o mestre do movimento. São Paulo: Summus, 2006.
PETRELLA, P. Prefácio. In: MOMENSOHN, M.; PETRELLA, P. (Orgs.). Reflexões sobre Laban, o mestre do movimento. São Paulo: Summus, 2006, p. 11-14.

RENGEL, L. Dicionário Laban. 2001. 138 f. Dissertação (Mestrado em Artes). Instituto de Artes, Universidade Estadual de Campinas, São Paulo. 2001.

Anadarco, 2014.

Dicionário Laban. 3a Ed. São Paulo:

ROPA, E. C. La danza e l'agitprop: I teatri-non-teatrali nella cultura tedesca del primo Novecento. Bolonha: II Mulino, 1988.

A dança e o agit-prop: os teatros não teatrais e a cultura alemã do início do século $X X$. Tradução de Matteo Bonfitto, Michele Schiocchet e Yedda Chaves. São Paulo: Perspectiva, 2014.

SCIALOM, M. Laban plural: um estudo genealógico do legado de Rudolf Laban no Brasil. 2009. $245 \mathrm{f}$. Dissertação (Mestrado em Artes Cênicas). Programa de Pós-Graduação em Artes Cênicas, Universidade Federal da Bahia, Salvador, Bahia.

Para que servem as estrelas? - um estudo sobre as interfaces do teatro-dança. Revista Científica FAP, v. 5, jan./jun. 2010, p. 191-205. Disponível em: < http://periodicos.unespar.edu.br/index.php/ revistacientifica/article/view/1580/920>. Acesso em 13/06/2020.

. Rudolf Laban in the 21st Century: a Brazilian perspective. 2015. 318 f. Tese (Doutorado em Dança). University of Roehampton, Londres, Inglaterra.

SOTRATTO, A. C.; SANDIM, C.; FRANÇA, J.; GIOVELLI, N. Coreodramaturgia: reflexões sobre a dança. 2007. 58 f. Trabalho de Conclusão de Curso (Graduação em Dança). Departamento de Artes Corporais, Instituto de Artes, Universidade Estadual de Campinas, Campinas, São Paulo. 
UNIVERSIDADE ESTADUAL DE CAMPINAS. Catálogo dos Cursos de Graduação. Campinas, 1995.

VIANNA, K. A dança. São Paulo: Siciliano, 1990.

Recebido: 15/06/2020

Aceito: $28 / 09 / 2020$

Aprovado para publicação: 10/12/2020

Este é um artigo de acesso aberto distribuído sob os termos de uma Licença Crea- tive Commons Atribuição 4.0 Internacional. Disponível em: $<$ http://creative commons.org/licenses/by/4.0>.

This is an open-access article distributed under the terms of the Creative Commons Attribution License 4.0 International. Available at: $<$ http://creative commons.org/licenses/by/4.0>.

Ce texte en libre accès est placé sous licence Creative Commons Attribution 4.0 International. Disponible sur: <http://creativecommons.org/licenses/by/4.0>. 